\title{
Evidence for Endothermic Ancestors of Crocodiles at the Stem of Archosaur Evolution
}

\author{
Roger S. Seymour ${ }^{1}$ \\ Christina L. Bennett-Stamper ${ }^{2}$ \\ Sonya D. Johnston ${ }^{1}$ \\ David R. Carrier ${ }^{3}$ \\ Gordon C. Grigg ${ }^{4}$ \\ ${ }^{1}$ Department of Environmental Biology, University of \\ Adelaide, Adelaide, South Australia 5005, Australia; ${ }^{2}$ Center \\ for Biological Microscopy, University of Cincinnati, 3125 \\ Eden Avenue, P.O. Box 670521, Cincinnati, Ohio 45267- \\ 0521; ${ }^{3}$ Department of Biology, University of Utah, Salt Lake \\ City, Utah 84112; ${ }^{4}$ Department of Zoology, University of \\ Queensland, Brisbane, Queensland 4072, Australia
}

Accepted 11/19/04

\begin{abstract}
Physiological, anatomical, and developmental features of the crocodilian heart support the paleontological evidence that the ancestors of living crocodilians were active and endothermic, but the lineage reverted to ectothermy when it invaded the aquatic, ambush predator niche. In endotherms, there is a functional nexus between high metabolic rates, high blood flow rates, and complete separation of high systemic blood pressure from low pulmonary blood pressure in a four-chambered heart. Ectotherms generally lack all of these characteristics, but crocodilians retain a four-chambered heart. However, crocodilians have a neurally controlled, pulmonary bypass shunt that is functional in diving. Shunting occurs outside of the heart and involves the left aortic arch that originates from the right ventricle, the foramen of Panizza between the left and right aortic arches, and the cog-tooth valve at the base of the pulmonary artery. Developmental studies show that all of these uniquely crocodilian features are secondarily derived, indicating a shift from the complete separation of blood flow of endotherms to the controlled shunting of ectotherms. We present other evidence for endothermy in stem archosaurs and suggest that some dinosaurs may have inherited the trait.
\end{abstract}

Physiological and Biochemical Zoology 77(6):1051-1067. 2004. (C) 2004 by The University of Chicago. All rights reserved. 1522-2152/2004/7706-3066\$15.00

\section{Introduction}

The distinction between endothermy and ectothermy is one of the central characteristics that divides vertebrate animals. Although there is variability in the timing, precision, and level of the endothermic state among birds and mammals, both groups are clearly distinguished from the majority of ectothermic reptiles, amphibians, and fish. Birds and mammals typically have considerably higher body temperatures, metabolic rates, and stamina. Their body temperatures are usually physiologically regulated within a narrow range, and their metabolic pathways are generally aerobic during rest and activity. Ectotherms are characterised by environmentally dependent body temperatures, low metabolic rates, and reliance on anaerobic pathways for intense but unsustainable activity. Probably because of the perceived dichotomy between living endotherms and ectotherms, the question of the metabolic status of extinct vertebrate groups has been extensively debated (Thomas and Olson 1980; Bakker 1986; Farlow et al. 1995; Feduccia 1999).

One line of evidence concerns the relationship between endothermy, metabolic rate, and a four-chambered heart. Loris S. Russell (1965), and possibly others before him, recognised that the four-chambered heart of archosaurs perfectly separates oxygenated and deoxygenated bloods, which should optimise gas transport by sending only deoxygenated blood to the lung and oxygenated blood to the body. Webb (1979) also drew attention to the significance of the four-chambered heart and elevated activity in the ancestors of birds and crocodiles. The inference is that higher metabolic rates of endotherms would select for the perfect separation of bloods. This argument was used in connection with the discovery of the disputed fossil four-chambered heart in an ornithischian dinosaur (Fisher et al. 2000). However, despite an anatomically incomplete separation of the chambers of noncrocodilian reptilian hearts, some snakes and lizards are able to reduce mixing to almost zero (Hicks 1998). This shows that a four-chambered heart is not necessary merely to separate bloods.

We believe that the primary role of the four-chambered heart is to separate systemic and pulmonary blood pressures, rather than just blood oxygenation states. To achieve high metabolic rates, endotherms require a greater cardiovascular oxygen transport capacity, which they realise with higher blood flow rates and hemoglobin levels. Elevated cardiac output in endotherms is associated with markedly higher systemic arterial blood pressure (Rodbard et al. 1949; Johansen 1972; Fig. 1). The explanation for their high systemic blood pressure and appreciable 


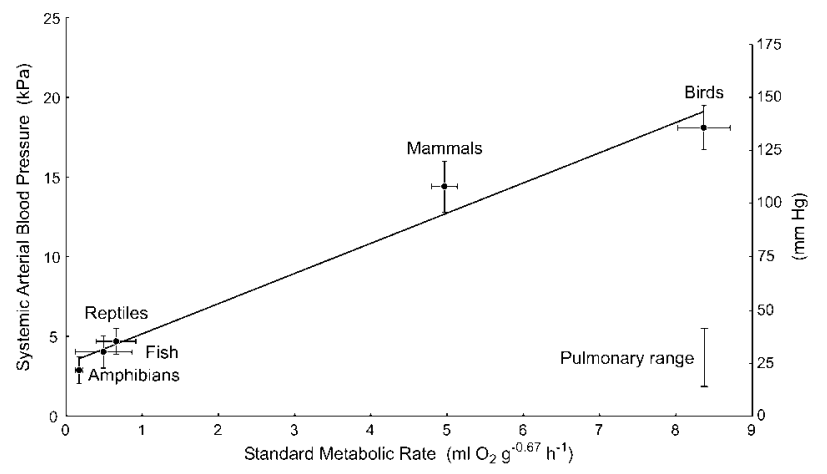

Figure 1. Systemic arterial blood pressures in relation to mass-independent standard metabolic rate among vertebrate groups. Statistics are means and 95\% confidence intervals. In fish, amphibians, reptiles, birds, and mammals, blood pressure is based on $23,6,25,12$, and 23 species, respectively; metabolic rate is based on $8,9,69,398$, and 639 species, respectively, from the literature. The range of pulmonary arterial blood pressures of air-breathing vertebrates is shown for comparison (Johansen 1972; Hicks 1998).

peripheral resistance is not entirely clear, but we will present possible functional roles below. At this point, however, we need only to observe the strong correlation. Pulmonary arterial blood pressures, on the other hand, remain low in both ectotherms and endotherms (Fig. 1). In these cases, it is generally accepted that high pulmonary blood pressures would cause excess fluid filtration into the air spaces (pulmonary edema) and inhibit gas exchange (Wang et al. 1998). Although the anatomically undivided hearts of some exceptional reptiles (e.g., monitor lizards and large terrestrial snakes) can generate appreciable pressure separation and moderately high pressures (Burggren and Johansen 1982; Seymour 1987; Wang et al. 2002, 2003), most reptiles have systemic systolic pressures that fall considerably short of the mammalian or avian norms (cf. Hicks 1998 for reptiles and Seymour and Blaylock 2000 for birds and mammals). Hearts of noncrocodilian reptiles rely on muscular force to keep opposing walls and ridges pressed together to achieve separation during systole; avian and mammalian fourchambered hearts do not. Thus, a four-chambered heart is the best solution for separating pressures. Despite a fourchambered heart and good separation of systemic and pulmonary pressures, the mean systemic blood pressures of conscious crocodilians are well within the ectothermic range: values for Alligator mississippiensis include $3.9 \mathrm{kPa}$ (Greenfield and Morrow 1961), $5.3 \mathrm{kPa}$ (White 1970), and $5.2 \mathrm{kPa}$ (Jones and Shelton 1993); those for Crocodylus porosus include $7.1 \mathrm{kPa}$ (Altimiras et al. 1998), $7.9 \mathrm{kPa}$ (Grigg and Johansen 1987), and $6.2 \mathrm{kPa}$ (Axelsson et al. 1997).

There are also considerable differences in relative heart size between endotherms and ectotherms. According to the principle of Laplace, high systemic blood pressures are correlated with thick-walled left ventricles and heavier hearts (Seymour and Blaylock 2000). Heart mass averages about $0.4 \%-0.7 \%$ of body mass in mammals and $0.8 \%-1.2 \%$ in birds (Poupa and Ostádal 1969; Bishop 1997; Seymour and Blaylock 2000), but it is only $0.19 \%-0.32 \%$ in most reptiles (Poupa and Lindström 1983; Seymour 1987; Farrell et al. 1998). In alligators, heart mass decreases from $0.25 \%$ at $1 \mathrm{~kg}$ body mass to $0.15 \%$ at 70 $\mathrm{kg}$ and $0.125 \%$ at $124 \mathrm{~kg}$ (Coulson et al. 1989).

The level of systemic arterial blood pressure is related not only to metabolic rate and heart size but also to the size of the animal. More specifically, although all of the heart's energy is ultimately lost to frictional resistance in the circulation, one immediate requirement of central systemic arterial blood pressure is to support the vertical blood column above the heart (Seymour et al. 1993). This requirement explains why the giraffe has an arterial blood pressure about twice the mammalian norm (Hargens 1987) and why arterial blood pressure increases significantly in larger mammals (Seymour and Blaylock 2000) and longer terrestrial snakes (Seymour 1987). Thus, it is possible to calculate the minimum arterial blood pressure of an animal from a skeletal reconstruction, assuming that the heart was in the sternal area and the blood column was the vertical distance above it. Estimates of systemic arterial blood pressures lie between 10 and $25 \mathrm{kPa}$ in some ornithopod and theropod dinosaurs (Seymour 1976) and possibly higher in some sauropods (Seymour and Lillywhite 2000). These measurements show that the hearts of dinosaurs were capable of producing systemic pressures well within the endothermic range, which would have required the functional separation of systemic and pulmonary blood in a four-chambered heart. However, the analysis cannot determine what led to the evolution of such a heart and high blood pressure; these features could have evolved initially in support of endothermy, large body size, or both. If it can be shown that they occurred first in short animals, it would be consistent with endothermy as the primary correlate.

This report expands an earlier presentation and provides evidence that the small ancestors of crocodiles possessed fourchambered hearts that were capable of generating high systemic blood pressures consonant with endothermy (Seymour 2001b). Ironically, the hearts of living ectothermic crocodilians provide compelling clues concerning the history of endothermy in the group. Although the hearts are relatively small and produce systemic blood pressures in the same range as other ectothermic reptiles, their structure and development testify to endothermic origins in basal archosaurs. Our study further supports the possibility of endothermy in dinosaurs that evolved from this group. The evidence we present is at first paleontological, to show how the anatomy of crocodilians changed from terrestrial to aquatic lifestyles. Then we discuss the cardiovascular physiology associated with aquatic behavior in reptiles. This leads to the insights derived from our developmental studies of the crocodilian heart. Finally, we discuss other lines of evidence that are consistent or inconsistent with our hypothesis. 


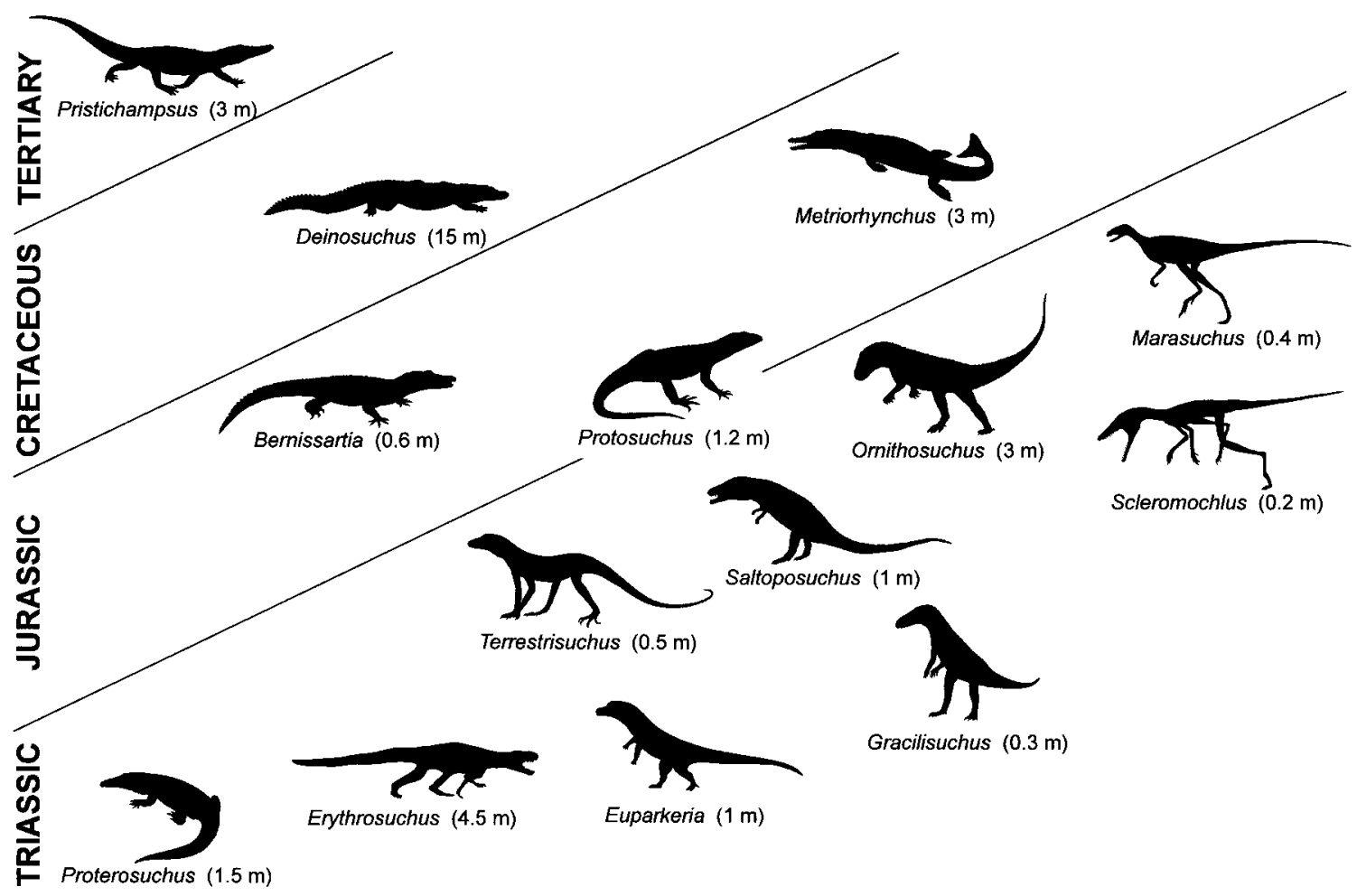

Figure 2. Two main lineages of archosaurs, the ancestors of crocodiles (Crurotarsi) and the ancestors of dinosaurs (Ornithodira), are outlined with selected genera mentioned in the text. Crurotarsans evolved after Euparkeria and include the four Triassic sphenosuchians and ornithosuchids above it. The true crocodilian lineage begins with Protosuchus in the Early Jurassic and extends to the Tertiary eucrocodilian Pristichampsus at the upper left. The two ornithodirans, Marasuchus and Scleromochlus at the right, represent the origins of the pterosaurs, dinosaurs, and birds. Ages, body forms, and nominal lengths are provided.

\section{Paleontological Evidence}

It is generally agreed that living crocodiles are archosaurs that have a lineage going back to the basal archosauriforms in the Late Permian (Lee 2001). The basal archosaurs and their relatives were once grouped as "thecodonts" because of shared characteristics including teeth in sockets and antorbital fenestrae, among others, but the relationships within this paraphyletic group have been clarified by recent cladistic analyses by several paleontologists (Benton 1990, 1997, 1999; Sereno 1991; Parrish 1997; Brochu 2001a, 2001b). The hypothesised evolution of basal archosaurs described below is a simplification based mainly on these authorities. While some semantic differences exist between them, and there remain some questions about the fine-scale affinities of certain groups, there is consensus on the overall phylogeny. Although the Archosauria might be considered to include only the crocodilian and dinosaur-avian lineages after the Triassic split, for convenience, we refer to all of the early archosauriforms as "basal archosaurs."

One of the oldest complete basal archosaur skeletons comes from the Early Triassic, the 1.5-m-long Proterosuchus, which resembled modern crocodiles (Fig. 2). The proterosuchids were followed in the Middle Triassic by the erythrosuchids, which became the most important terrestrial predators of the time, reaching lengths of $4.5 \mathrm{~m}$. Then came Euparkeria, a small $(\sim 1$ $\mathrm{m})$, agile archosaur that is usually considered to be close to the common ancestor of crocodilians and dinosaurs. In the Middle Triassic, archosaurs split into two lineages: Crurotarsi (crocodilians and relatives) and Ornithodira (dinosaurs, birds, pterosaurs, and relatives). By the Late Triassic, there were a large number of crurotarsans, including phytosaurs (crocodilian-like piscivores), aetosaurs (armoured, terrestrial herbivores), and rauisuchians (large, theropod-like terrestrial carnivores). However, living crocodiles appear to be more distantly related to these groups than to the basal crocodylomorphs of the Late Triassic, including the small ( $\sim 0.5-1.5 \mathrm{~m})$ sphenosuchians (e.g., Sphenosuchus, Saltoposuchus, Gracilisuchus, and Terrestrisuchus). The tiny Erpetosuchus appears to be among the closest sister group of the Crocodylomorpha (Benton and Walker 2002). The other line of archosaur evolution, the ornithodirans, began with relatively small $(\sim 20-50 \mathrm{~cm})$ species, including Marasuchus (=Lagosuchus) and Scleromochlus (Benton 1999). 
While these are not considered the progenitors of crocodiles, they are from the Triassic and close to the split defining the crown-clade Archosauria (Sereno 1991; Brochu 2001b). The ornithosuchids (e.g., Ornithosuchus and Riojasuchus) are another group of basal archosaurs that also appear to be close to the division between crurotarsans and ornithodirans.

The crocodyliform lineage of crurotarsans appeared in the Early Jurassic, exemplified by Protosuchus $(\sim 1 \mathrm{~m})$ and Orthosuchus $(\sim 1 \mathrm{~m})$, and it underwent a massive radiation throughout the Jurassic and Cretaceous. This lineage is traditionally classified into successive protosuchians, mesosuchians, and finally eusuchians, but only Eusuchia is not paraphyletic (Brochu 2003). Some of these Jurassic crocodyliforms were highly aquatic, in marine and freshwater habitats, and others were wholly terrestrial. The eusuchians appeared in the Cretaceous, presumably derived from aquatic ancestors because of their morphological similarities to living species. Some eusuchians became large, reaching 8 tons in mass and perhaps $12 \mathrm{~m}$ in length, and they possibly fed on terrestrial dinosaurs at the water's edge (Sereno et al. 2001).

Along the lineage from basal archosaur to eusuchians, there are two overall trends that are significant to the present hypothesis: a general increase in the range of body size and a shift from terrestrial to amphibious lifestyles. Basal archosaurs of the Triassic were relatively small, compared to the eusuchian and dinosaurian giants of the Cretaceous (Fig. 2). The skeletal features of Euparkeria, Erpetoshuchus, the sphenosuchians, the ornithosuchids, and the early ornithodirans are suggestive of cursoriality: hip and shoulder joints capable of positioning the legs in parasagittal planes, delicate and sometimes long limb bones, and disproportionate fore- and hindlimb lengths that indicate at least facultative bipedalism. This description fits the basal crocodylomorphs but not the advanced ones. The fossil evidence shows that locomotion shifted from running to swimming (Parrish 1987). Among the crocodyliforms, there was a trend toward reduction in the dermal armour and development of procoelous vertebrae, both associated with a loss of the laterally stiffened trunk valuable for cursorial (especially bipedal) locomotion and the development of increased lateral movement of axial swimming (Salisbury and Frey 2001). Mesosuchians and eusuchians developed secondary palates that allow breathing when the mouth is open underwater (Iordansky 1973). Thus, the fossils imply a shift from cursorial predation on land in the Triassic to a primarily aquatic niche of ambush predator by the Cretaceous.

The limbs of basal ornithodirans are so long and disproportionate that some authors suggested that they bounded about the landscape (Walker 1970; Benton 1999). Today, bounding locomotion, often called galloping, occasionally occurs in adult Crocodylus johnstoni (Webb and Gans 1982), juvenile Crocodylus niloticus (Cott 1961), and Crocodylus porosus (Zug 1974). The sagittal flexing of the spine and limbs has been described as similar to that of a cheetah at full speed. Grahame
Webb and Carl Gans (1982) speculated that bounding behavior might be ancient. However, we know that bounding behavior cannot be tolerated for long periods in living crocodilians, because strenuous activity is supported anaerobically (Seymour et al. 1985; Baldwin et al. 1995). Crocodiles now use bounding only for short dashes to water. Today, bounding ancestry may also be reflected in embryonic or juvenile forms. The hindlimbs develop more quickly than the forelimbs in crocodiles, bipedal birds, and jumping anurans, while the forelimbs develop first in other quadrupedal vertebrates (Dodson 1975; M. Richardson, personal communication). The jumping, insectivorous habits of juvenile crocodilians give way to sit-and-wait habits of the adults (C. Gans, personal communication). These ontogenetic shifts in form and behavior mirror the phylogenetic shift from terrestrial to aquatic behavior of crocodilians. That adult crocodilians had to retain some terrestrial adaptations can be explained by their need to lay their cleidoic eggs on land. Water in the pores of the eggshell suffocates the embryos (Webb et al. 1983).

The evolutionary history of crocodilians is consistent with an endothermic origin giving way to an ectothermic condition. Upright stance and the capacity for highly active, terrestrial behavior are characteristic of endotherms. Although fossils reveal posture and locomotion, however, they cannot definitely prove the level and sustainability of activity. Bakker (1986) concluded that the basal archosaurs were endotherms, based on several lines of paleontological evidence, including upright stance, low predator-prey ratios, bone histology, and the apparent competitive domination by the archosaurs over presumably endothermic protomammals (therapsids). It has turned out that none of these lines of evidence in itself has provided a conclusive case for endothermy in basal archosaurs (Bennett and Ruben 1986). On the other hand, neither has the case for ectothermy been proven.

\section{Physiology of Aquatic Reptiles}

Living crocodilians demonstrate a suite of physiological features that serve their behavior of sit-and-wait predation in water (Seymour 1982). Whether they eat fish or terrestrial animals, crocodilians benefit from long breath-hold dives, because they can remain cryptic before they capture prey and stay submerged while they subdue it. Obviously, an aquatic predator that drowns terrestrial prey must be able to hold its breath for a longer time than the victim. Breath holding in crocodiles is accompanied by several characteristics that can lengthen diving time by reducing oxygen consumption and increasing tolerance to anaerobic metabolism.

\section{Ectothermy}

Resting rates of oxygen consumption are 6-10 times lower in reptiles than in mammals or birds at comparable body size and 
temperature (Bennett and Dawson 1976; Peters 1983). In water, moreover, body temperatures of reptiles are considerably lower than those of most endotherms, further reducing metabolic rate by a factor of perhaps two. Modal body temperatures of Crocodylus porosus range between about $27^{\circ} \mathrm{C}$ and $31^{\circ} \mathrm{C}$ in winter and summer, respectively, under field conditions when the animals are engaged in basking during the day (Grigg et al. 1998; Seebacher et al. 1999). Ectothermy is therefore an important feature of diving reptiles that lengthens dives, and it should be of selective advantage in aquatic predators. Ectothermy is also an energetically advantageous strategy for an ambush or stealth predator, because there is no requirement for the slow or motionless animal to maintain a high body temperature against the high thermal conductivity and heat capacity of water. There are no living endotherms that feed like crocodiles.

\section{Large Body Size}

Because oxygen stores in the blood, lung and muscle volumes are nearly proportional to body size, but metabolic rate scales allometrically with an exponent of about 0.7 (Peters 1983), diving time should be proportional to body mass raised to roughly the power of 0.3 . This means that for every order of magnitude body mass increases, aerobic dive time is approximately doubled. Larger predators are not only able to remain under the water longer, they are also stronger and better able to subdue larger prey.

\section{High Anaerobic Capacity}

Ectothermic reptiles rely more highly on anaerobic metabolism than any other animal group (Bennett and Dawson 1976). While the aerobic pathway is able to support relatively sluggish activity, anaerobic metabolism takes over during intense activity. Maximal activity levels (measured as locomotor speeds) of reptiles can match the levels of many endotherms, but anaerobiosis leads to accumulation of lactic acid and acid-base disturbance. To avoid incapacitation by fatigue, selection has favored a high tolerance to the products of anaerobic metabolism in reptiles. Diving would be expected to promote further reliance on anaerobic pathways and tolerance to acid metabolites. An aquatic sit-and-wait predator might rely on aerobiosis while stalking and anaerobiosis while fighting underwater.

Crocodilians in particular show an exceptionally high reliance on anaerobic metabolism. Anaerobic capacity increases in larger C. porosus: animals about $1 \mathrm{~kg}$ fatigue in about $5 \mathrm{~min}$ of strenuous exercise, but those above $100 \mathrm{~kg}$ can last an hour or so (Bennett et al. 1985). Blood lactate levels rise to $20 \mathrm{mmol}$ $\mathrm{L}^{-1}$ in Alligator mississippiensis (Coulson and Hernandez 1979) and above $50 \mathrm{mmol} \mathrm{L}^{-1}$ in C. porosus (Bennett et al. 1985), the latter possibly being the highest concentration ever recorded in a vertebrate as a result of activity. Lactate rises higher only in turtles asphyxiated for a day or more (Ultsch and Jackson 1982). Crocodylus porosus can survive blood $\mathrm{pH}$ dropping to 6.42 , in contrast to most reptiles, which are fatigued or dead when pH drops much below 7.0 (Seymour et al. 1985). Muscle $\mathrm{pH}$ can drop below 6.0 in large C. porosus, possibly setting the limit on anaerobic capacity (Baldwin et al. 1995).

\section{Central Vascular Shunting}

The incompletely divided hearts of noncrocodilian reptiles potentially permit mixing of oxygenated blood from the lung with deoxygenated blood from the body. When mixing occurs, the flow of blood from one side to the other is called a "shunt." It is possible to observe deoxygenated blood returning from the body in systemic veins being shunted out to the body again in the systemic arteries - a so-called pulmonary bypass shunt, or right-to-left shunt, because the shunted blood moves from the right to the left side of the heart. Left-to-right shunts can also occur when some of the oxygenated blood from the lung is recirculated to it. Causes, controls, and correlations of shunting have been intensively studied in reptiles, particularly in connection to diving or breathing patterns (see reviews by Seymour [1982], Burggren [1985], and Hicks [1998]). It can be concluded that there is a wide variation in patterns of shunting between species and physiological states. In general, however, there is good evidence that little shunting occurs in reptiles breathing normally in air, but pulmonary bypass shunts can develop during voluntary diving and especially during enforced dives under laboratory conditions.

Despite their completely divided, four-chambered hearts, crocodilians can develop pulmonary bypass shunts. But unlike noncrocodilian reptiles that shunt within the ventricles, crocodilians shunt through a unique arrangement of the outflow vessels of the heart (Webb 1979; Farrell et al. 1998). Both right and left aortic arches are present, as in other reptiles, but the left one originates from the right ventricle, while the right one originates from the left ventricle (Fig. 3). The foramen of Panizza connects the right and left arches above their bicuspid valves. The pulmonary artery also connects to the right ventricle, but uniquely in crocodilians, the pulmonary blood passes through two valves, first a cog-tooth valve that can restrict flow and then a leaf valve that prevents reverse flow. Finally, the right and left arches join by an anastomosing vessel posterior to the heart.

The pattern of blood flow during nonshunting and shunting in crocodiles has been the focus of many studies (for reviews see White 1970, Grigg 1989, Axelsson and Franklin 1997, and Axelsson 2001). Under nonshunting conditions, flow from the right ventricle goes only into the pulmonary artery; the valve to the left arch remains closed, because the pressure in the left arch is always greater than that in the right ventricle. Blood from the left ventricle flows into the right arch, and some of this can pass through the foramen of Panizza into the left arch, 


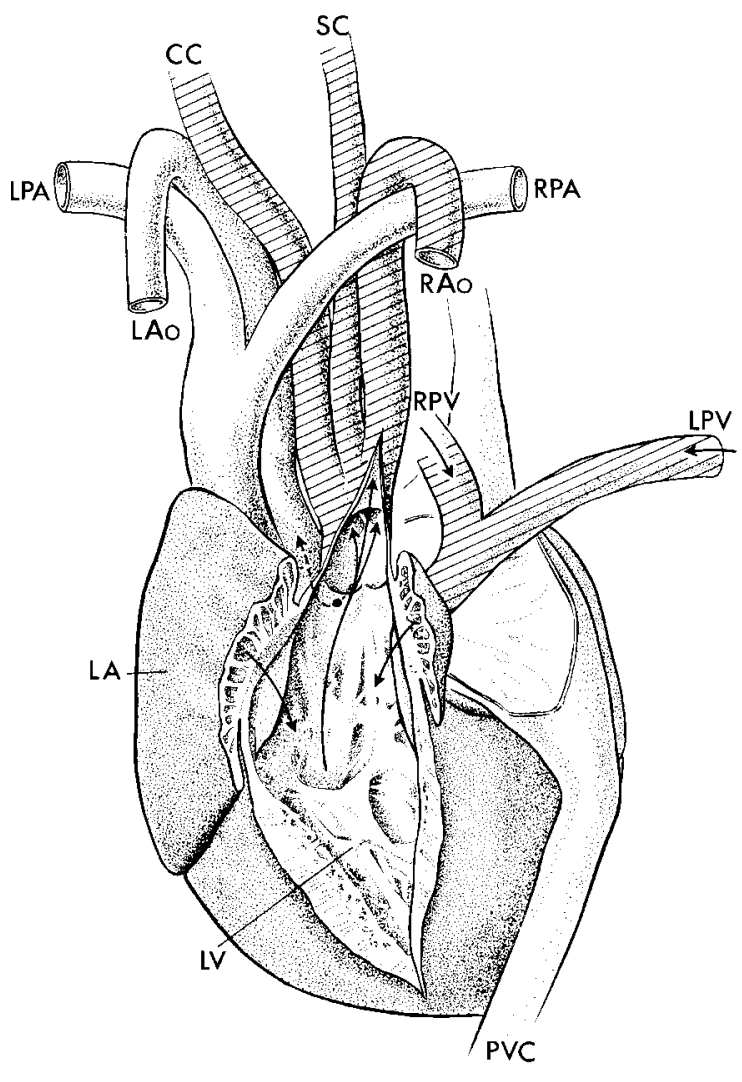

Dorsal View

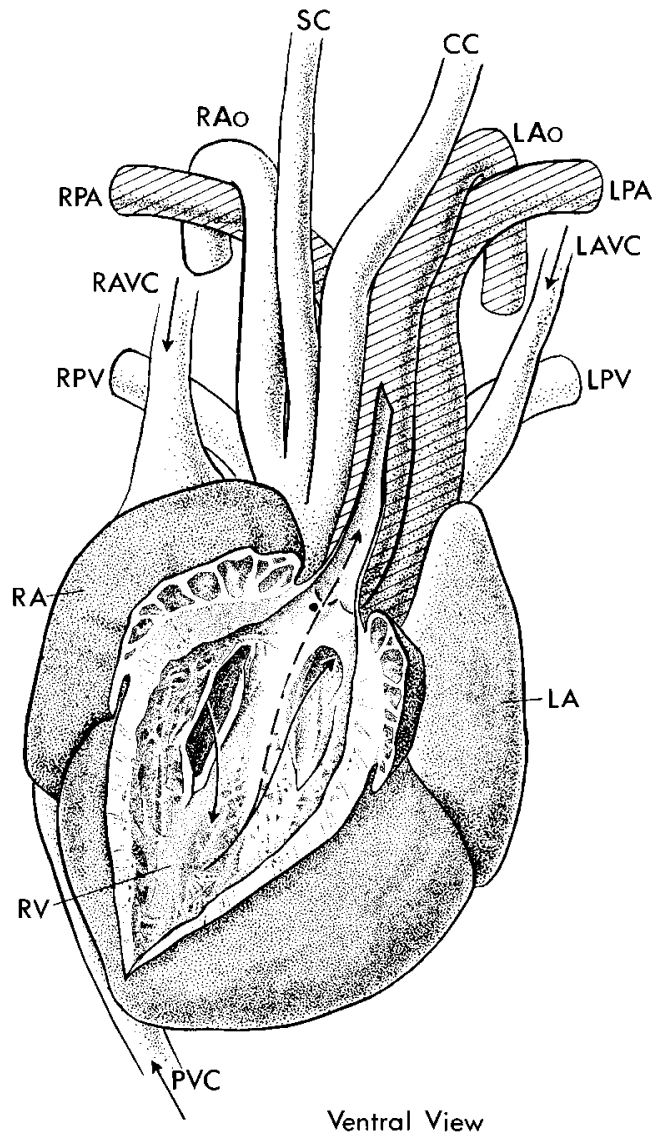

Figure 3. Chambers and outflow vessels of the crocodilian heart (Grigg 1989). $L V, R V, L A, R A=$ left and right ventricle and atrium. $L P A, R P A$, $L P V, R P V=$ left and right pulmonary artery and vein. $S C=$ subclavian artery. $C C=$ common carotid artery. $L A V C, R A V C=$ left and right anterior vena cava. $P V C=$ postcaval vein. $L A o, R A o=$ left and right aortic arches. The position of the foramen of Panizza is indicated by a dot at the base of the aortic arches. The hatching indicates vessels that connect to the open ventricle.

especially during diastole. Blood can also pass between arches across the anastomosis behind the heart. Regardless of variability in the division and timing of flow events, there is complete separation of oxygenated and deoxygenated bloods when the valve to the left arch remains closed. Under shunting conditions, however, contraction of the cog-tooth valve causes pressure in the right ventricle to exceed that in the left arch, and its bicuspid valve opens. Blood ejected into the left arch goes mainly to the gut, but there is evidence that an appreciable amount can go in the reverse direction through the foramen of Panizza into the right arch. The proximal left arch is wide, in contrast to more distal segments, suggesting that a large volume of right ventricular blood can pass through the foramen (Grigg 1991).

Shunting is certainly controlled in crocodilians. It is initiated by contraction of the cog-tooth valve at the base of the pulmonary conus. This increases the resistance of the outflow tract, consequently increasing right ventricular pressure and opening the valve to the left arch. The cog-tooth valve operates as a variable resistor under nervous control. Adrenergic stimulation relaxes the cog-tooth valve, probably keeping it open during conditions of stress or exercise (Franklin and Axelsson 2000). Shunts developing during diving bradycardia may involve cholinergic effects on the valve (White 1969, 1970; Axelsson et al. 1989; Jones and Shelton 1993), perhaps in sympathy with falling systemic blood pressure (Shelton and Jones 1991). The size of the foramen of Panizza is also controlled, with adrenergic stimulation decreasing its diameter while vasoactive intestinal polypeptide (VIP) increases it (Axelsson and Franklin 2001). Although cholinergic effects have not been tested on the foramen of Panizza, if acetylcholine acts like VIP, then one would have the situation in which diving bradycardia is associated with contraction of the cog-tooth valve and relaxation of the foramen of Panizza, both promoting a pulmonary bypass shunt. 
Shunting has been suggested as being involved with several reptilian characteristics, including behavioral thermoregulation (Baker et al. 1972), postprandial gut perfusion (Jones and Shelton 1993), cutaneous gas exchange (Seymour 1982), pulmonary filtration (Burggren 1982), and pulmonary gas exchange (White et al. 1989; Hicks 1998). Although the roles of shunting have been extensively debated (White 1970; Burggren 1985; Hicks 1998), it is clear that shunting exists in crocodiles and that it is associated with their unique anatomy and physiology. Shunt pathways are large, not vestigial, and they are neurally controlled. Their persistence in crocodilians is highly indicative of an adaptive value. In the diving context, shunting reduces systemic arterial oxygen tension, which can affect metabolic rate by inducing a hypometabolic state.

\section{Hypometabolism}

Reduction in aerobic metabolic rate below normal can conserve oxygen during a dive. Studies of aquatic turtles have shown that diving is associated with increased pulmonary bypass shunting, leading to a decrease in arterial $\mathrm{Po}_{2}$ (Burggren and Shelton 1979; White et al. 1989). Exposure to hypoxic gas (Hicks and Wang 1999) or vagal stimulation (Platzack and Hicks 2001) also results in low arterial $\mathrm{Po}_{2}$, decreased systemic oxygen transport, and a reduction in metabolic rate of anaesthetised Trachemys scripta. This hypometabolic state is considered to be an active downregulation rather than a simple failure of oxygen delivery to mitochondria. Hypometabolism, whether derived from shunting or general hypoxia, is clearly advantageous for extending dives. But shunting may be a more effective mechanism, because it can induce hypometabolism earlier in a dive, when considerable oxygen stores remain in the lungs. Without the shunt, hypometabolism could only be initiated late in the dive, when most oxygen reserves have been exhausted. Unfortunately, there are no data on the relationship between shunting and metabolic rates for crocodilians.

\section{Crocodile Heart Development}

The control of shunting in crocodiles is dependent on four anatomical features that are unique among reptiles: (1) completely divided ventricles, (2) a left arch originating from the right ventricle, (3) a cog-tooth valve at the origin of the pulmonary artery, and (4) a foramen of Panizza. Insight into the evolution of these features may be gained from a study of heart development. The argument we apply here is that de novo developments of a right ventricular origin of the left aortic arch, the foramen of Panizza, and the cog-tooth valve in embryonic crocodilians represent secondarily evolved features (apomorphies). This hypothesis should not be rejected by association with Haeckel's Biogenetic Law, which proposed that the adult stages of phylogenetic history are present in the embryo (ontogeny recapitulates phylogeny). In fact, vertebrate em- bryos do not show adult phylogenetic characteristics, and there is no common stage through which all vertebrate embryos pass (Richardson et al. 1997). It is nevertheless recognised that there is a great deal of similarity in the scheme of morphological development of embryonic stages within a group of animals and that evolution can occur either by introducing new characters into the scheme (caenogenesis) or by changing the timing of events (heterochrony; de Beer 1958; Gould 1977). In particular, the early stages of the vertebrate heart are simple tubes, but differences appear later, by loss or addition of features (Goodrich 1958). When it occurs, heterochrony can involve transposition of developmental events of unrelated organ systems, but within each system, transpositions do not generally occur. There are several examples of the development of individual characters and even character suites that support recapitulation (Gould 1977; Richardson and Keuck 2002). Although Haeckel considered caenogenesis and heterochrony to be adaptations by the embryo to its circumstances, these changes can have origins early in development but are not subject to selection until later (Richardson 1999). We hypothesise, therefore, that late development of the foramen of Panizza and cog-tooth valve in crocodilian embryos would be examples of caenogenesis associated with the secondary evolution of shunting capability.

The embryology of vertebrate hearts is well known, including specific studies of crocodilians by Greil (1903), Hochstetter (1906), Reese (1915), Wettstein (1954), Goodrich (1958), Shaner (1962), and Ferguson (1985). The authorities agree that the early and intermediate developmental stages are the same in crocodilians and other vertebrates. The heart begins as a single tube that bends on itself, forming a sinus venosus, atrium, ventricle, bulbus, and ventral aorta. The ventral aorta in turn branches into several aortic arches. Two septa that grow toward the heart from the bases of specific arches progressively divide the aorta and bulbus (Fig. 4). The pulmo-aortic septum gradually separates the pulmonary artery from the left arch, and the interaortic septum separates left and right arches. Meanwhile, a muscular interventricular septum grows toward the bulbus and begins to separate the right and left ventricles. The intermediate result is a three-chambered ventricle with three outflow vessels, each with valves and all connecting to a common chamber, as seen in noncrocodilian reptiles. The interaortic septum may remain perforated in noncrocodilian reptiles - whether above the aortic valves (Young et al. 1993) or below them (Webb 1979) is not certain-but these perforations are not homologous to the foramen of Panizza of crocodilians (Webb 1979). From this point, the crocodilian heart is unique among reptiles, because it proceeds to form a membranous septum that grows from the muscular ventricular septum, across the common chamber, and into the wall between the right and left arches, thus completely separating the left and right ventricles (Fig. 5).

Remarkably, details of the appearance of the foramen of 


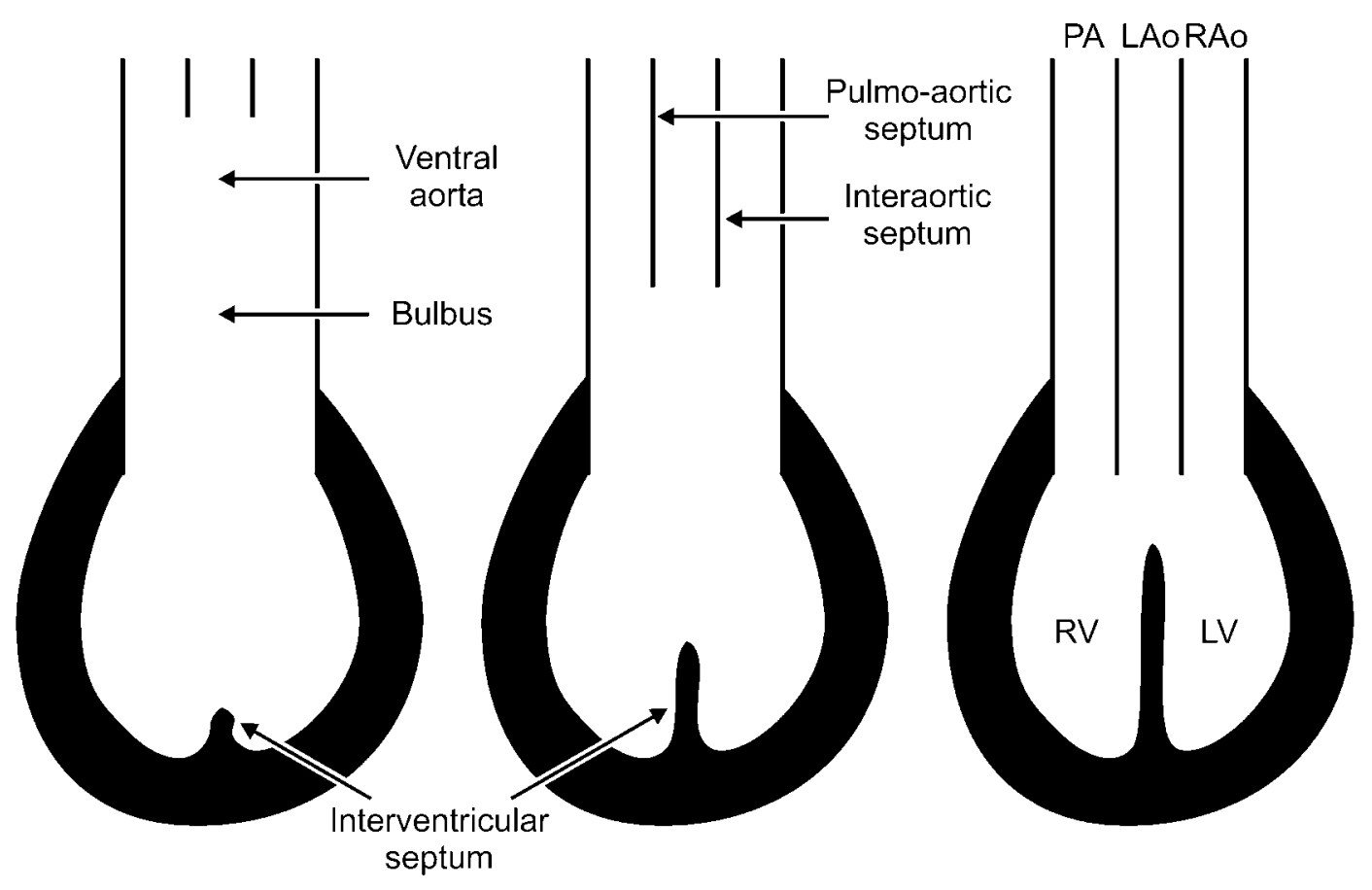

Figure 4. Schematic of cardiac development in reptiles, showing the progressive caudad development of the pulmo-aortic and interaortic septa and the craniad development of the muscular interventricular septum. The final stage includes three ventricular chambers and is typical of noncrocodilian reptiles.

Panizza and cog-tooth valve are either lacking or contradictory in the literature. In a monumental comparison of vertebrate heart development, Greil (1903) described the appearance of the foramen of Panizza as a secondary perforation of the interaortic septum in the caiman. But Goodrich (1958) pronounced that the foramen was more likely formed by a failure of the interaortic septum to close completely during its growth toward the heart. Greil's description more strongly supports the hypothesis of a secondary development of shunting, because the foramen is clearly a novel feature. Goodrich's explanation does not refute the hypothesis (the foramen could be paedomorphic), but it is weaker, because all reptiles go through a stage of incomplete division of the aortae. None of the other embryological accounts comments further on the appearance of the foramen of Panizza, and significantly, none mentions or shows any structure resembling the cog-tooth valve. To resolve the matter, we have investigated heart development in Alligator mississippiensis (Bennett-Stamper 2003) and Crocodylus porosus (R. S. Seymour, S. D. Johnston, and S. I. C. Runciman, unpublished manuscript). We used standard wax histological techniques on intermediate and final stages of development.

The results from the alligator align well with previous descriptions, namely, that the two septa in the bulbus grow toward the heart and that the muscular interventricular septum progressively divides the ventricle. They also clearly confirm Greil's observation that the foramen of Panizza is a secondary per- foration in the complete interaortic septum (Fig. 6). The foramen first appears at stage 21 (Ferguson 1985) as a dimple in the septum behind the medial valve cusp of the right arch. This dimple deepens between stages 22 and 23 and opens by stage 24 or 25 , at about $50 \mathrm{~d}$ of incubation. Hatching in alligators occurs at stage 27-28, at about $65 \mathrm{~d}$. The foramen of Panizza was unfortunately already open in the youngest $C$. porosus embryo examined, at stage 25 on day 60 of an 80 -d incubation period. However, serial sections of the pulmonary conus in both species revealed leaflike bicuspid valves, but no evidence of cog-tooth nodules below it at any stage, including hatchlings (Fig. 7). Webb (1979) also failed to find nodules in C. porosus hatchlings, but they were apparent in 1.1-m-long juveniles. It is clear that cog-tooth valves appear and begin to function well after hatching. These observations support a secondary appearance of shunting anatomy in crocodilians.

The details of membranous septum development differ between crocodilians, birds, and mammals, but the pattern of circulation is critically dependent on where it joins the three outflow vessels (Shaner 1962). It joins between the left and right arches in crocodiles. In birds, it joins between the pulmonary artery and the left arch, but the latter quickly atrophies, leaving the right arch as the only systemic supply. It is significant that the avian heart does not pass through a crocodilian stage, with the left arch opening into the right ventricle, but this anomaly occurs often enough to have been noticed by avian 


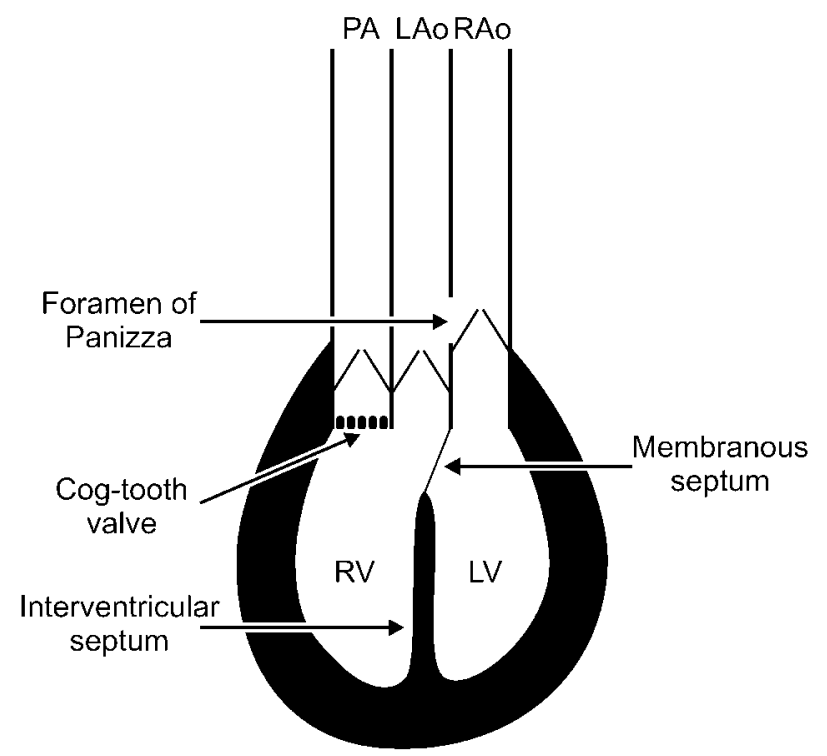

Figure 5. Schematic of the crocodilian heart, with ventricles completely separated by the interventricular and membranous septa. The foramen of Panizza connects the left and right aortic arches ( $L A o$ and $R A o$, respectively), and a cog-tooth valve lies beneath leaf valves in the pulmonary artery $(P A)$.

embryologists (Bremer 1928). The similarity between avian and reptilian hearts makes it easy to visualise evolution from a common ancestor by a simple shift in the membranous septum (Webb 1979). In mammals, failure of the membranous septum to join in the correct place creates the most common congenital septal defects, including the Tetralogy of Fallot and complete transposition of the pulmonary artery and aorta (Becker and Anderson 1981). Humans can even retain both right and left aortic arches, provided that sufficient blood is passed through them during development. These congenital abnormalities can have a multifactorial genetic basis, as evidenced by a small, but significant, risk of familial recurrence (Pierpont and Moller 1986). The prevalence of such defects suggests that only a minor developmental alteration of the membranous septum can result in large differences in final cardiac design. Whether a left aorta persists and what chamber it connects to may depend on genetic switches that determine where the membranous septum fuses with the wall. In conclusion, the persistence of the left aortic arch and its connection to the right ventricle in crocodilians does not involve a great modification in heart development. It simply depends on the site of attachment of the membranous septum, and this location can easily shift. In concert with the secondary development of the foramen of Panizza and cog-tooth valve, such a shift completes the appearance of a novel shunting mechanism in crocodilians consistent with a reversion to ectothermy.

\section{Other Evidence for Endothermic Ancestors}

\section{Lung Structure}

Crocodilians have multichambered lungs with a complex arrangement of internal connecting tubes. The striking similarity in design between crocodilian and avian lungs has been well recognised but difficult to explain (see references in Perry 1990). Embryonic crocodilian lungs show two sets of chambers growing from the primary bronchi: a cranial and a caudal set. Perry (1990) proposes that these may be homologs of avian secondary bronchi. As in birds, the caudal set grows over the cranial set, and the perforations between adjacent chambers in an adult crocodilian lung could be homologs of avian tertiary bronchi (parabronchi). This arrangement sets crocodilian lungs apart from multicameral lungs that occur in other reptiles, such as the lizards Varanus and Heloderma and the turtle Trachemys.

It is clear that the complexity of crocodilian lungs is not matched by their ability to transport respiratory gases. In juvenile Crocodylus niloticus, the effective exchange surface area is small and the mean harmonic tissue thickness is relatively large, so that the anatomical diffusing capacity is the lowest for reptiles (Perry 1990). Perry (1990) recognised that the current complexity could have resulted from a conservative genome but found it difficult to rationalise, other than to suggest that perhaps the complexity in juveniles becomes useful as the animals grow to great size. However, we feel that crocodilian lung structure may be an atavistic trait inherited from highly aerobic, endothermic ancestors. During evolution as ectotherms, the surface area has decreased and barrier thickness has increased, but the overall structure has not greatly changed.

\section{Lung Ventilation during Locomotion}

Carrier (1987a) described seven characteristics associated with the ability to breathe and enhance stamina during locomotion: (1) diaphragmatic muscles, (2) enlarged transverse processes and epaxial muscles, (3) bipedal locomotion, (4) upright posture, (5) bounding gait, (6) lateral stability of the vertebral column, and (7) endothermy. This suite evolved in the synapsids, leading to recent mammals, and in the diapsids, leading to recent birds. Carrier (1987a) pointed out that at least elements 1, 2, 4, and 5 are evident in living crocodilians and that, along with a four-chambered heart and a reduced fifth digit on the pes, these characteristics are inconsistent with the present low stamina and ectothermy. He proposed that a shift in lifestyle, from terrestrial endothermy to the amphibious ectothermy, could explain these features of crocodilians.

Recent observations on American alligators indicate that crocodilians do breathe effectively during terrestrial locomotion (Farmer and Carrier 2000a, 2000b, 2000c). Lung ventilation of resting alligators is typical of ectothermic tetrapods, consisting of intermittent breaths of moderate tidal volume. During exercise, however, the ventilation pattern of alligators is more 

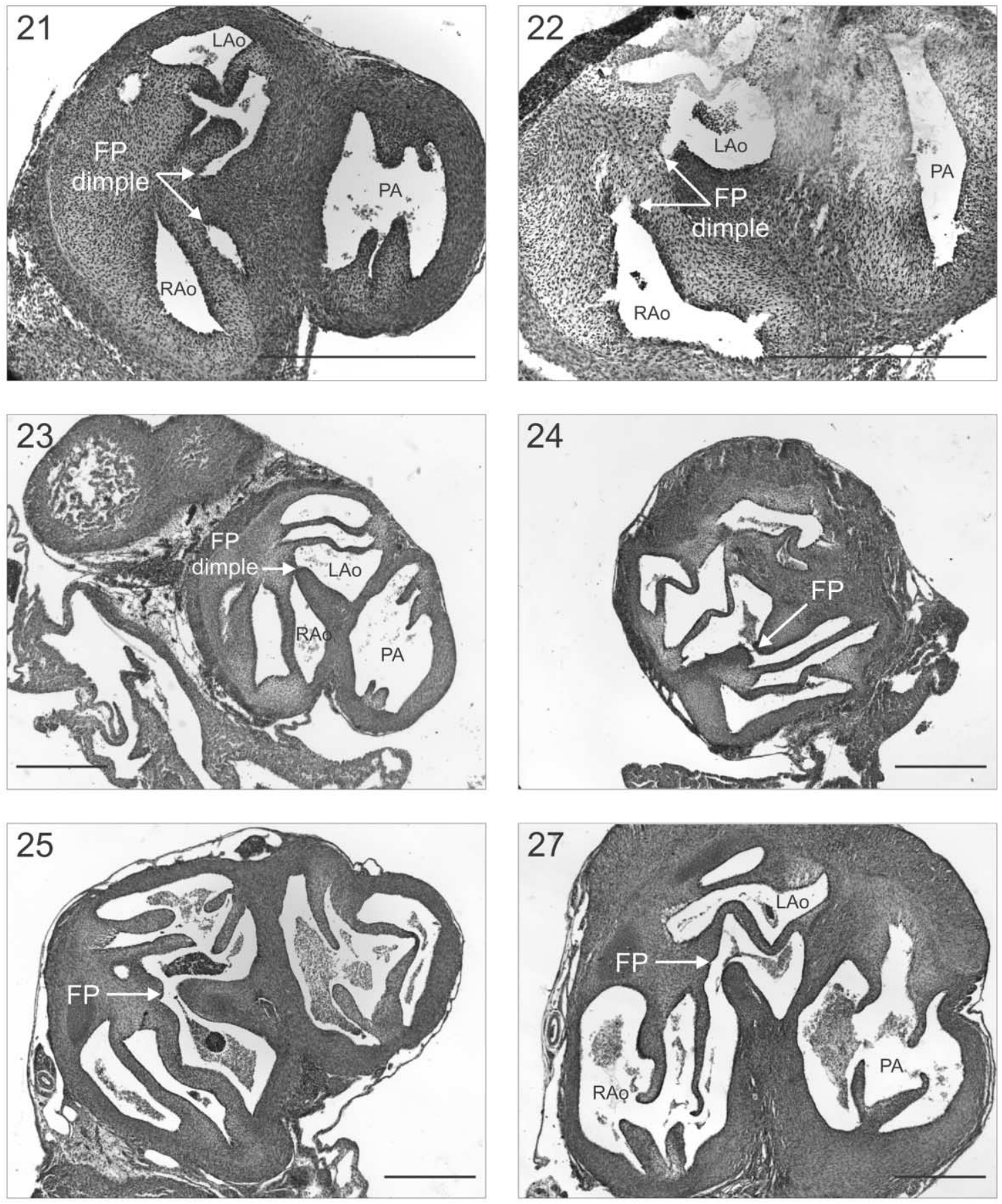

Figure 6. Transverse sections through the developing heart of Alligator mississippiensis at selected late Ferguson (1985) stages. Three outflow vessels are evident: the pulmonary artery $(P A)$ and the left and right aortic arches ( $L A o$ and $R A o$, respectively). The foramen of Panizza ( $F P$ ) begins as a dimple in the septum in stages $21-23$, breaks through at about stage 24 , and is enlarged by hatching stage 27 . Note that the bicuspid leaf valves can form up to three lumina in each vessel. The scale bar is $500 \mu \mathrm{m}$. 

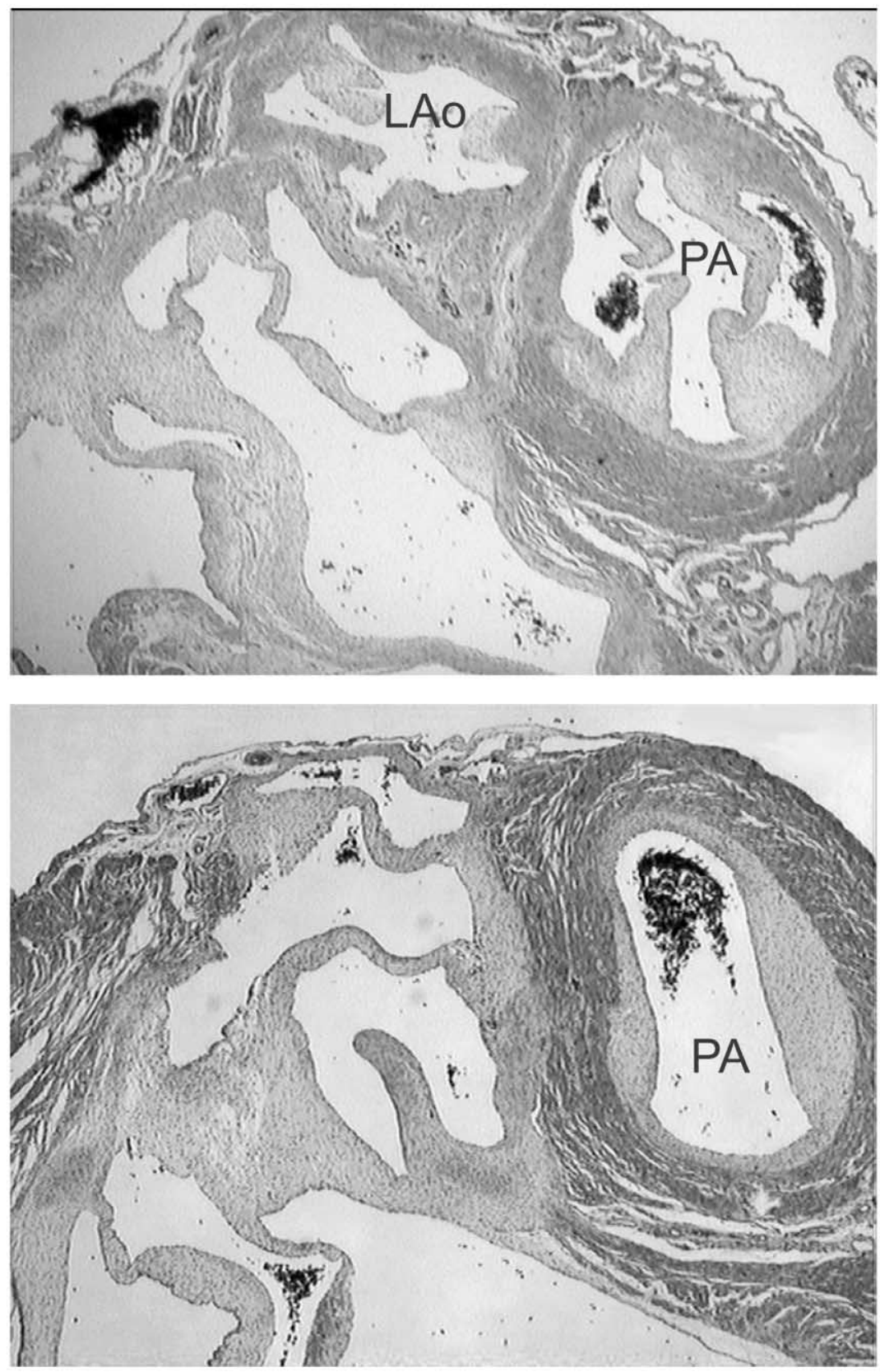

Figure 7. Transverse section through the heart of a hatchling Crocodylus porosus. The leaves of the valve in the pulmonary artery ( $P A)$ are visible at the top right, next to the left aortic arch $(L A o)$. In the lower panel, the smooth walls of the pulmonary conus below the leaf valves reveal only the endothelial cushions and no evidence of a cog-tooth valve.

similar to that of birds or mammals than that of other ectotherms. In alligators, tidal volume during walking increases as much as fourfold above that before exercise. The mass-specific tidal volumes of young alligators appear to represent the largest breaths reported for any animal during exercise, and the rate of ventilation greatly exceeds that required for gas exchange.
This ability to breathe effectively during terrestrial locomotion is significant, given the suggestion that the ancestors of basal crocodylomorphs were unable to run and breathe at the same time (Carrier 1987a, 1991; Carrier and Farmer 2000a, $2000 b$ ). In animals with a sprawling limb posture, the actions of the axial muscles to produce costal ventilation appear to be 
antagonistic to the locomotor actions required from these same muscles to produce lateral bending of the trunk and postural stability. Such a locomotor constraint on costal ventilation is present in lizards (Carrier 1987b, 1991; Wang et al. 1997; Owerkowicz et al. 1999). Nevertheless, the factors suggested as disrupting costal ventilation in running lizards are also present in walking alligators (albeit to a lesser degree): a semierect posture and lateral bending of the trunk. Given the conflicting actions of axial muscles in a sprawling or semisprawling tetrapod, what factors allow alligators to breathe during terrestrial locomotion?

Crocodilians have a highly derived system of lung ventilation. Most dramatically, they possess a specialised ventilatory muscle, the diaphragmaticus, which is instrumental in the production of inspiration and is largely, or entirely, independent of locomotion (Boelaert 1942; Naifeh et al. 1970; Gans and Clark 1976; Farmer and Carrier 2000a). Two other hypaxial muscles that played important roles in the locomotion of basal tetrapods, the rectus abdominis and transversus abdominis, serve primarily a ventilatory function in alligators (Farmer and Carrier 2000a). Finally, crocodilians possess a derived pelvic musculoskeletal system that actively expands the abdominal cavity, allowing caudal displacement of the viscera during inspiration (Carrier and Farmer 2000a, 2000b; Farmer and Carrier 2000a). This suite of derived characters associated with ventilation during locomotion is hard to reconcile with the low metabolic requirements and sit-and-wait lifestyle of modern crocodilians. These specializations for ventilation are associated with selection early in the evolution of the crocodilian lineage for a high aerobic activity metabolism and an ability to run and breathe at the same time.

\section{Bone}

Fibrolamellar bone, typified by extensive vascularization, is a characteristic of birds and mammals, and its presence in dinosaurs was one of the original lines of evidence for endothermy (de Ricqlès 1974). However, the fact that juvenile alligators produce fibrolamellar bone has been put forward as one of the flaws of this argument (Reid 1997). Full-term embryonic alligators have even more fibrolamellar bone than juveniles (Horner et al. 2001). This feature could, in fact, be a vestigial trait from endothermic ancestors, or it could be common among neonate amniotes and have nothing to do with endothermy. However, a recent survey of bone histology of fossil archosauriforms reveals that bone structure and growth patterns of phytosaurs, aetosaurs, and rauisuchians were similar to those in living crocodilians but that Terrestrisuchus and Erythrosuchus had bone structure more similar to that of dinosaurs, birds, and mammals (de Ricqlès et al. 2003). It is significant that Erythrosuchus is the oldest specimen in the analysis, and that Terrestrisuchus represents the first of the crocodylomorphs (Brochu 2001b). De Ricqlès et al. (2003) could not avoid the conclusion that bone correlated with high metabolic rate was ancestral among archosaurs and that some early groups subsequently abandoned the trait. This view is consistent with our hypothesis that the crocodilians also lost endothermy when they became aquatic in the Jurassic.

\section{Molecular Clock}

It has been argued that the pace of genetic change is affected by differences in body temperature such that endotherms would show higher rates of divergence than ectotherms (Martin and Palumbi 1993). Crocodilians, in fact, show relatively higher rates of divergence in the mitochondrial genome than do other ectotherms (Kumazawa and Nishida 1995; Quinn and Mindell 1996; Janke and Arnason 1997; Janke et al. 2001). This fact has even been used to disprove the relationship between body temperature and the speed of the molecular clock (Janke and Arnason 1997; Janke et al. 2001). But it is equally possible that the large divergence is due to a faster clock during the first part of crocodilian evolution. On the other hand, because divergence rates are higher in alligatorids than in nonalligatorids (Brochu 2001b), the molecular clock may not depend wholly on body temperature differences.

\section{Contrary Evidence}

Practically all living mammals and birds possess respiratory turbinates in the nasal passages. These thin bones with a large surface area have been related to endothermy, because they function to condition the air breathed by the animal and conserve heat and water by temporal countercurrent exchange (Schmidt-Nielsen et al. 1970). During inspiration, cold air is warmed and humidified before it is drawn into the lungs. Inspiration cools the turbinates by direct heat transfer and evaporation. During expiration, when the warm, humid air from the lungs again passes by the cool turbinates, the air loses heat and some of its water vapor, which condenses on the walls. The result is that the exhaled air is cooler and drier than it would have been if the turbinates were not present or the animal exhaled through the mouth.

The presence or absence of respiratory turbinates in fossils has been promoted as a solid indicator of the endothermic or ectothermic status of fossil animals (Ruben et al. 1997). Their absence in living crocodiles has been associated with undeniable ectothermy, and their absence in dinosaurs speaks against endothermy (Ruben et al. 1996). Similarly, the presumed presence of turbinates among the cynodont group of protomammals is consistent with the first appearance of endothermy in mammalian phylogeny (Hillenius 1994). Nevertheless, this argument relies on three assumptions: (1) the space in the nasal passages is a good indication of presence or absence of turbinates in animals whose fossils often do not preserve them; (2) the pattern of air flow through the passages did not include any of 
the large "olfactory" sinuses in fossil skulls; (3) respiratory turbinates are essential for endothermy to counteract otherwise high rates of heat and water loss. These are reasonable assumptions, but there are incongruities that raise some doubt. The small nasal volumes in theropod dinosaurs suggest ectothermy, but insulation indicates otherwise (Xu et al. 1999a, 1999b). The first bird Archaeopteryx was presumably an endotherm but has nasal profiles similar to those of theropod dinosaurs. Living nectarivorous birds and mammals that have an overabundance of water in their diets possess respiratory turbinates, and cetaceans in polar marine environments where water and cold stresses are severe do not. There is also significant countercurrent exchange in the nostrils of lizards, but not to the same extent as in birds and mammals (Murrish and Schmidt-Nielsen 1970). It is apparent that turbinates are not a strict requirement for endothermy, especially in equable environments with ample water availability.

There is no indication that basal archosaurs or early crocodilians were ever well insulated externally. However, like the turbinate argument, the absence of any evidence does not prove that they were not insulated or that they could not have been endotherms. Insulation does not easily fossilise, as demonstrated by the majority of featherless Archaeopteryx specimens (Feduccia 1999) and the rarity of feathered theropod dinosaur fossils (Xu et al. 1999a, 1999b). Furthermore, there are many endotherms alive today without much external insulation, for example, humans, many other mammals, leatherback turtles (Paladino et al. 1990), incubating pythons (Vinegar et al. 1970; Harlow and Grigg 1984), warm-bodied fish (Carey et al. 1971), many endothermic insects (Bartholomew and Heinrich 1978), and thermogenic flowers (Seymour 2001a). If sufficient energy is available, endothermy is possible without obvious insulation.

\section{Conclusions}

Throughout the continuing debate on the evolution of endothermy and particularly the metabolic status of dinosaurs, a common underlying assumption is that endotherms evolved from ectotherms. The reverse, ectotherms evolving from endotherms, has rarely been considered (de Ricqlès 1978; Carrier 1987a; de Ricqlès et al. 2003). It is unclear whether this reluctance stems from the obvious direction of evolution in vertebrates in general (ectothermic fish to endothermic birds and mammals) or a chauvinistic bias that endotherms are somehow more advanced or superior. However, there is no reason why reverse evolution is unlikely, and in fact it is not uncommon among typical endotherms. Not only are there numerous examples of facultative ectothermy in mammals and birds that hibernate or undergo daily torpor, there are mammals with highly labile body temperatures and metabolic rates that are routinely in the ectothermic range (Jarvis 1978; Seymour et al.
1998). In cases such as these, where the lifestyle permits it, and especially where energy in the environment is limited, one should expect selection for relaxation or complete abandonment of endothermy.

The evidence presented here supports the hypothesis that the ancestors of crocodilians were endothermic. The key element in the argument is their four-chambered heart, which could separate the high systemic blood pressures from low pulmonary blood pressures in ancestors. There are several explanations for a high systemic pressure: to produce the high flow rates of more viscous, high-hematocrit blood associated with high rates of aerobic activity, to enable sufficient ultrafiltration in the kidneys and tissues, to force blood through contracting muscles, and to permit greater distributional control of perfusion between differently active vascular beds. Many of these functions are associated with the high metabolic rates of endotherms.

Another function of high systemic blood pressure is to support a vertical blood column above the heart against gravity (Seymour et al. 1993). The only animals known to have evolved large body size and erect stance are endotherms. No terrestrial ectotherm sustains a vertical distance of $1 \mathrm{~m}$ or more between the heart and head. This distance is equivalent to an arterial blood pressure gradient of about $10 \mathrm{kPa}$ just to support the column, and an additional pressure is required to move the blood through the vascular beds. Because many basal archosaurs had erect stance but were small, it seems unlikely that their four-chambered hearts were originally used to overcome the effects of gravity. It is more reasonable to believe that separation of systemic and pulmonary pressures was first associated with endothermy.

Evolution back to ectothermy may have benefited crocodilians as aquatic ambush predators, but there is no obvious selective advantage for some smaller members of the dinosaur lineage to abandon endothermy. Many of them remained fully terrestrial, active predators that would have been well served by endothermy, and they gave rise to endothermic birds. By the same reasoning, small terrestrial herbivorous dinosaurs that were preyed upon might have been disadvantaged if they were ectothermic and lacked the protection that water afforded the crocodilians. It therefore seems likely that endothermy evolved in the stem archosaurs and was passed on to many of their descendants. Having a high systemic blood pressure for endothermy in turn permitted terrestrial, bipedal dinosaurs to become large and erect, because the four-chambered heart could develop enough pressure to support a substantial vertical blood column to the head (Seymour 1976). Nevertheless, endothermy in dinosaurs may have been restricted to the smaller species, which do not have the level of inertial homeothermy characteristic of the giants (Seebacher 2003). Proposed ectothermy in large sauropods or hadrosaurs, therefore, may represent additional cases of evolution from endothermic ancestors. 


\section{Acknowledgments}

We appreciate the assistance, discussions, and advice from many people that led to this synthesis: Michael Benton, Christopher Brochu, Dane Crossley, Chris Daniels, Colleen Farmer, Craig Franklin, Carl Gans, Jim Hicks, Willem Hillenius, Mike Lee, Tomasz Owerkowicz, Nicole Phillips, Michael Richardson, John Ruben, Sue Runciman, Frank Seebacher, John Spicer, Lucy Sullivan, Tobias Wang, Steve Warburton, Grahame Webb, and Craig White. These people did not necessarily read the manuscript or agree with all of the points, but they were influential. The research was supported by the Australian Research Council.

\section{Literature Cited}

Altimiras J., C.E. Franklin, and M. Axelsson. 1998. Relationships between blood pressure and heart rate in the saltwater crocodile Crocodylus porosus. J Exp Biol 201:2235-2242.

Axelsson M. 2001. The crocodilian heart: more controlled than we thought? Exp Physiol 86:785-789.

Axelsson M. and C.E. Franklin. 1997. From anatomy to angioscopy: 164 years of crocodilian cardiovascular research, recent advances, and speculations. Comp Biochem Physiol A 118:51-62.

- 2001. The calibre of the foramen of Panizza in Crocodylus porosus is variable and under adrenergic control. J Comp Physiol B 171:341-346.

Axelsson M., C.E. Franklin, R. Fritsche, G.C. Grigg, and S. Nilsson. 1997. The sub-pulmonary conus and the arterial anatomosis as important sites of cardiovascular regulation in the crocodile Crocodylus porosus. J Exp Biol 200:807-814.

Axelsson M., S. Holm, and S. Nilsson. 1989. Flow dynamics of the crocodilian heart. Am J Physiol 256:R875-R879.

Baker L.A., W.W. Weathers, and F.N. White. 1972. Temperature induced peripheral blood flow changes in lizards. J Comp Physiol 80:313-323.

Bakker R.T. 1986. The Dinosaur Heresies. Longman Scientific \& Technical, Essex.

Baldwin J., R.S. Seymour, and G.J.W. Webb. 1995. Scaling of anaerobic metabolism during exercise in the estuarine crocodile (Crocodylus porosus). Comp Biochem Physiol A 112: 285-293.

Bartholomew G.A. and B. Heinrich. 1978. Endothermy in African dung beetles during flight, ball making, and ball rolling. J Exp Biol 73:65-83.

Becker A.E. and R.H. Anderson. 1981. Pathology of Congenital Heart Disease. Butterworths, London.

Bennett A.F. and W.R. Dawson. 1976. Metabolism. Pp. 127223 in C. Gans and W.R. Dawson, eds. Physiology A. Academic Press, London.

Bennett A.F. and J.A. Ruben. 1986. The metabolic and thermoregulatory status of therapsids. Pp. 207-218 in N.I. Hotton, P.D. MacLean, J.J. Roth, and E.C. Roth, eds. The Ecology and Biology of Mammal-Like Reptiles. Smithsonian Institution, Washington, D.C.

Bennett A.F., R.S. Seymour, D.F. Bradford, and G.J.W. Webb. 1985. Mass-dependence of anaerobic metabolism and acidbase disturbance during activity in the salt-water crocodile, Crocodylus porosus. J Exp Biol 118:161-171.

Bennett-Stamper C. 2003. Structural development of the foramen of Panizza in embryonic alligators. MSc thesis. New Mexico State University.

Benton M.J. 1990. Origin and interrelationships of dinosaurs. Pp. 11-30 in D.B. Weishampel, P. Dodson, and H. Osmólska, eds. The Dinosauria. University of California Press, Berkeley. - 1997. Vertebrate Palaeontology. Chapman \& Hall, London.

- 1999. Scleromochlus taylori and the origin of dinosaurs and pterosaurs. Philos Trans R Soc Lond B 354:1423-1446.

Benton M.J. and A.D. Walker. 2002. Erpetosuchus, a crocodilelike basal archosaur from the Late Triassic of Elgin, Scotland. Zool J Linn Soc 136:25-47.

Bishop C.M. 1997. Heart mass and the maximum cardiac output of birds and mammals: implications for estimating the maximum aerobic power input of flying animals. Philos Trans R Soc Lond B 352:447-456.

Boelaert R. 1942. Sur la physiologie de la respiration de l'Alligator mississipiensis. Arch Int Physiol Biochim 52:57-72.

Bremer J.L. 1928. Part I. An interpretation of the development of the heart. Part II. The left aorta of reptiles. Am J Anat 42:307-369.

Brochu C.A. 2001a. Congruence between physiology, phylogenetics and the fossil record on crocodylian historical biogeography. Pp. 9-28 in G.C. Grigg, F. Seebacher, and C.E. Franklin, eds. Crocodilian Biology and Evolution. Surrey Beatty, Chipping Norton.

- 2001b. Progress and future directions in archosaur phylogenetics. J Paleontol 75:1185-1201.

- 2003. Phylogenetic approaches toward crocodylian history. Annu Rev Earth Planet Sci 32:357-397.

Burggren W. 1982. Pulmonary plasma filtration in the turtle: a wet vertebrate lung? Science 215:77-78.

. 1985. Hemodynamics and regulation of central cardiovascular shunts in reptiles. Pp. 121-136 in K. Johansen and W.W. Burggren, eds. Cardiovascular Shunts. Munksgaard, Copenhagen.

Burggren W.W. and K. Johansen. 1982. Ventricular hemodynamics in the monitor lizard Varanus exanthematicus: pulmonary and systemic pressure separation. J Exp Biol 96:343354.

Burggren W.W. and G. Shelton. 1979. Gas exchange and transport during intermittent breathing in chelonian reptiles. J Exp Biol 82:75-92.

Carey F.G., J.M. Teal, J.W. Kanwisher, and K.D. Lawson. 1971. Warm-bodied fish. Am Zool 11:137-145.

Carrier D.R. 1987a. The evolution of locomotor stamina in 
tetrapods: circumventing a mechanical constraint. Paleobiology 13:326-341.

1987b. Lung ventilation during walking and running in four species of lizards. Exp Biol 47:33-42.

-1991. Conflict in the hypaxial musculo-skeletal system: documenting an evolutionary constraint. Am Zool 31:644656.

Carrier D.R. and C.G. Farmer. 2000a. The evolution of pelvic aspiration in archosaurs. Paleobiology 26:271-293.

- 2000b. The integration of ventilation and locomotion in archosaurs. Am Zool 40:87-100.

Cott H.B. 1961. Scientific results of an inquiry into the ecology and economic status of the Nile crocodile (Crocodilus niloticus) in Uganda and Northern Rhodesia. Trans Zool Soc Lond 29:211-356.

Coulson R.A., J.D. Herbert, and T.D. Coulson. 1989. Biochemistry and physiology of alligator metabolism in vivo. Am Zool 29:921-934.

Coulson R.A. and T. Hernandez. 1979. Factors controlling glycogen breakdown in the alligator. Comp Biochem Physiol C 64:115-121.

de Beer G. 1958. Embryos and Ancestors. Oxford University Press, Oxford.

de Ricqlès A. 1974. Evolution of endothermy: histological evidence. Evol Theory 1:51-80.

1978. Sur la classification, la signification fonctionnelle et l'histoire des tissus osseux des tétrapodes. 3ième partie: évolution. Ann Paléontol 64:85-111.

de Ricqlès A.J., K. Padian, and J.R. Horner. 2003. On the bone histology of some Triassic pseudosuchian archosaurs and related taxa. Ann Paléontol 89:67-101.

Dodson P. 1975. Functional and ecological significance of relative growth in Alligator. J Zool (Lond) 175:315-355.

Farlow J.O., P. Dodson, and A. Chinsamy. 1995. Dinosaur biology. Annu Rev Ecol Syst 26:445-471.

Farmer C.G. and D.R. Carrier. 2000a. Pelvic aspiration in the American alligator (Alligator mississippiensis). J Exp Biol 203: 1679-1687.

- 2000b. Ventilation and gas exchange during recovery from treadmill-locomotion in the American alligator (Alligator mississippiensis). Respir Physiol 120:67-73.

- 2000c. Ventilation and gas exchange during walking in the American alligator (Alligator mississippiensis). J Exp Biol 203:1671-1678.

Farrell A.P., A.K. Gamperl, and E.T.B. Francis. 1998. Comparative aspects of heart morphology. Pp. 375-424 in C. Gans and A.S. Gaunt, eds. Morphology G: Visceral Organs. Society for the Study of Amphibians and Reptiles, Ithaca, N.Y.

Feduccia A. 1999. The Origin and Evolution of Birds. Yale University Press, New Haven, Conn.

Ferguson M.W.J. 1985. Reproductive biology and embryology of the crocodilians. Pp. 329-492 in C. Gans, F. Billett, and P.F.A. Maderson, eds. Development A. Wiley, New York.
Fisher P.E., D.A. Russell, M.K. Stoskopf, R.E. Barrick, M. Hammer, and A.A. Kuzmitz. 2000. Cardiovascular evidence for an intermediate or higher metabolic rate in an ornithischian dinosaur. Science 288:503-505.

Franklin C.E. and M. Axelsson. 2000. An actively controlled heart valve. Nature 406:847-848.

Gans C. and B. Clark. 1976. Studies on ventilation of Caiman crocodilus (Crocodilia: Reptilia). Respir Physiol 26:285-301.

Goodrich E.S. 1958. Studies on the Structure and Development of Vertebrates. Dover, New York.

Gould S.J. 1977. Ontogeny and Phylogeny. Harvard University Press, Cambridge, Mass.

Greenfield L.J. and A.G. Morrow. 1961. The cardiovascular hemodynamics of Crocodilia. J Surg Res 1:97-103.

Greil A. 1903. Beiträge zur vergleichenden Anatomie und Entwicklungsgeschichte des Herzens und des Truncus arteriosus der Wirbelthiere. Gegenbaurs Morphol Jahrb 31:123-310.

Grigg G. 1989. The heart and patterns of cardiac outflow in Crocodilia. Proc Aust Physiol Pharmacol Soc 20:43-57.

- 1991. Central cardiovascular anatomy and function in Crocodilia. Pp. 339-353 in S.C. Wood, R.E. Weber, A.R. Hargens, and R.W. Millard, eds. Physiological Adaptations in Vertebrates: Respiration, Circulation, and Metabolism. Dekker, New York.

Grigg G.C. and K. Johansen. 1987. Cardiovascular dynamics in Crocodylus porosus breathing air and during voluntary aerobic dives. J Comp Physiol B 157:381-392.

Grigg G.C., F. Seebacher, L.A. Beard, and D. Morris. 1998. Thermal relations of large crocodiles, Crocodylus porosus, free-ranging in a naturalistic situation. Proc R Soc Lond B Biol Sci 265:1793-1799.

Hargens A.R. 1987. Gravitational cardiovascular adaptation in the giraffe. Physiologist 30(suppl.):S15-S18.

Harlow P. and G.C. Grigg. 1984. Shivering thermogenesis in the brooding diamond python, Python spilotes spilotes. Copeia 1984:959-965.

Hicks J.W. 1998. Cardiac shunting in reptiles: mechanisms, regulation, and physiological functions. Pp. 425-483 in C. Gans and A.S. Gaunt, eds. Biology of the Reptilia. Morphology G: Visceral Organs. Society for the Study of Amphibians and Reptiles, Ithaca, N.Y.

Hicks J.W. and T. Wang. 1999. Hypoxic hypometabolism in the anesthetized turtle, Trachemys scripta. Am J Physiol 277:R18R23.

Hillenius W.J. 1994. Turbinates in therapsids: evidence for Late Permian origins of mammalian endothermy. Evolution 48: 207-229.

Hochstetter F. 1906. Die Entwickelung des Blutgefässsystems. Pp. 21-166 in O. Hartwig, ed. Handbuch der vergleichenden und experimentellen Entwickelungslehre der Wirbeltiere. Fischer, Jena.

Horner J.R., K. Padian, and A.J. de Ricqlès. 2001. Comparative osteohistology of some embryonic and perinatal archosaurs: 
developmental and behavioral implications for dinosaurs. Paleobiology 27:39-58.

Iordansky N.N. 1973. The skull of the Crocodilia. Pp. 201-262 in C. Gans and T.S. Parsons, eds. Biology of the Reptilia. Academic Press, London.

Janke A. and U. Arnason. 1997. The complete mitochondrial genome of Alligator mississippiensis and the separation between recent archosauria (birds and crocodiles). Mol Biol Evol 14:1266-1272.

Janke A., D. Erpenbeck, M. Nilsson, and U. Arnason. 2001. The mitochondrial genomes of the iguana (Iguana iguana) and the caiman (Caiman crocodylus): implications for amniote phylogeny. Proc R Soc Lond B Biol Sci 268:623-631.

Jarvis J.U.M. 1978. Energetics of survival in Heterocephalus glaber (Rüppell), the naked mole-rat (Rodentia: Bathyergidae). Bull Carnegie Mus Nat Hist 6:81-87.

Johansen K. 1972. Heart and circulation in gill, skin, and lung breathing. Respir Physiol 14:193-210.

Jones D.R. and G. Shelton. 1993. The physiology of the alligator heart: left aortic flow patterns and right-to-left shunts. J Exp Biol 176:247-269.

Kumazawa Y. and M. Nishida. 1995. Variations in mitochondrial tRNA gene organization of reptiles as phylogenetic markers. Mol Biol Evol 12:759-772.

Lee M.S.Y. 2001. Molecules, morphology, and the monophyly of diapsid reptiles. Contrib Zool 70:1-22.

Martin A.P. and S.R. Palumbi. 1993. Body size, metabolic rate, generation time, and the molecular clock. Proc Natl Acad Sci USA 90:4087-4091.

Murrish D.E. and K. Schmidt-Nielsen. 1970. Exhaled air temperature and water conservation in lizards. Respir Physiol 10:151-158.

Naifeh K.H., S.E. Huggins, and H.E. Hoff. 1970. The nature of the ventilatory period in crocodilian respiration. Respir Physiol 10:338-348.

Owerkowicz T., C.G. Farmer, J.W. Hicks, and E.L. Brainerd. 1999. Contribution of gular pumping to lung ventilation in monitor lizards. Science 284:1661-1663.

Paladino F.V., M.P. O’Connor, and J.R. Spotila. 1990. Metabolism of leatherback turtles, gigantothermy, and thermoregulation of dinosaurs. Nature 344:858-860.

Parrish J.M. 1987. The origin of crocodilian locomotion. Paleobiology 13:396-414.

1997. Evolution of the archosaurs. Pp. 191-203 in J.O. Farlow and M.K. Brett-Surman, eds. The Complete Dinosaur. Indiana University Press, Bloomington.

Perry S.F. 1990. Gas exchange strategy in the Nile crocodile: a morphometric study. J Comp Physiol B 159:761-769.

Peters R.H. 1983. The Ecological Implications of Body Size. Cambridge University Press, Cambridge.

Pierpont M.E.M. and J.H. Moller. 1986. Congenital cardiac malformations. Pp. 13-24 in M.E.M. Pierpont and J.H.
Moller, eds. Genetics of Cardiovascular Disease. Martinus Nijhoff, Boston.

Platzack B. and J.W. Hicks. 2001. Reductions in systemic oxygen delivery induce a hypometabolic state in the turtle Trachemys scripta. Am J Physiol 281:R1295-R1301.

Poupa O. and L. Lindström. 1983. Comparative and scaling aspects of heart and body weights with reference to blood supply of cardiac fibers. Comp Biochem Physiol A 76:413-421.

Poupa O. and B. Ostádal. 1969. Experimental cardiomegalies and "cardiomegalies" in free-living animals. Ann N Y Acad Sci 136:445-468.

Quinn T.W. and D.P. Mindell. 1996. Mitochondrial gene order adjacent to the control region in crocodile, turtle, and tuatara. Mol Phylogenet Evol 5:344-351.

Reese A.M. 1915. The Alligator and Its Allies. Knickerbocker, New York.

Reid R.E.H. 1997. Dinosaurian physiology: the case for "intermediate” dinosaurs. Pp. 449-473 in J.O. Farlow and M.K. Brett-Surman, eds. The Complete Dinosaur. Indiana University Press, Bloomington.

Richardson M.K. 1999. Vertebrate evolution: the developmental origins of adult variation. BioEssays 21:604-613.

Richardson M.K., J. Hanken, M.L. Gooneratne, C. Pieau, A. Raynaud, L. Selwood, and G.M. Wright. 1997. There is no highly conserved embryonic stage in the vertebrates: implications for current theories of evolution and development. Anat Embryol 196:91-106.

Richardson M.K. and G. Keuck. 2002. Haeckel's ABC of evolution and development. Biol Rev 77:495-528.

Rodbard S., F. Brown, and L.N. Katz. 1949. The pulmonary arterial pressure. Am Heart J 38:863-871.

Ruben J.A., W.J. Hillenius, N.R. Geist, A. Leitch, T.D. Jones, P.J. Currie, J.R. Horner, and G. Espe. 1996. The metabolic status of some Late Cretaceous dinosaurs. Science 273:12041207.

Ruben J.A., A. Leitch, W. Hillenius, N. Geist, and T. Jones. 1997. New insights into the metabolic physiology of dinosaurs. Pp. 505-518 in J.O. Farlow and M.K. Brett-Surman, eds. The Complete Dinosaur. Indiana University Press, Bloomington.

Russell L.S. 1965. Body temperature of dinosaurs and its relationships to their extinction. J Paleontol 39:497-501.

Salisbury S.W. and E. Frey. 2001. A biomechanical transformation model for the evolution of semi-spheroidal articulations between adjoining vertebral bodies in crocodilians. Pp. 85-134 in G.C. Grigg, F. Seebacher, and C.E. Franklin, eds. Crocodilian Biology and Evolution. Surrey Beatty, Chipping Norton.

Schmidt-Nielsen K., F.R. Hainsworth, and D.E. Murrish. 1970. Counter-current heat exchange in the respiratory passages: effect on water and heat balance. Respir Physiol 9:263-276.

Seebacher F. 2003. Dinosaur body temperatures: the occurrence of endothermy and ectothermy. Paleobiology 29:105-122. 
Seebacher F., G.C. Grigg, and L.A. Beard. 1999. Crocodiles as dinosaurs: behavioural thermoregulation in very large ectotherms leads to high and stable body temperatures. J Exp Biol 202:77-86.

Sereno P.C. 1991. Basal archosaurs: phylogenetic relationships and functional implications. J Vertebr Paleontol 11:1-53.

Sereno P.C., H.C.E. Larsson, C.A. Sidor, and B. Gado. 2001. The giant crocodyliform Sarcosuchus from the Cretaceous of Africa. Science 294:1516-1519.

Seymour R.S. 1976. Dinosaurs, endothermy, and blood pressure. Nature 262:207-208.

1982. Physiological adaptations to aquatic life. Pp. 151 in C. Gans and F.H. Pough, eds. Biology of the Reptilia. Physiology D: Physiological Ecology. Academic Press, New York.

- 1987. Scaling of cardiovascular physiology in snakes. Am Zool 27:97-109.

- 2001a. Biophysics and physiology of temperature regulation in thermogenic flowers. Biosci Rep 21:223-236.

- 2001b. Preface to "Physiology and physiological ecology.” Pp. 263-264 in G.C. Grigg, F. Seebacher, and C.E. Franklin, eds. Crocodilian Biology and Evolution. Surrey Beatty, Chipping Norton.

Seymour R.S., A.F. Bennett, and D.F. Bradford. 1985. Blood gas tensions and acid-base regulation in the salt-water crocodile, Crocodylus porosus, at rest and after exhaustive exercise. J Exp Biol 118:143-159.

Seymour R.S. and A. Blaylock. 2000. The principle of Laplace and scaling of blood pressure and ventricular wall stress in mammals and birds. Physiol Biochem Zool 73:389-405.

Seymour R.S., A.R. Hargens, and T.J. Pedley. 1993. The heart works against gravity. Am J Physiol 265:R715-R720.

Seymour R.S. and H.B. Lillywhite. 2000. Hearts, neck posture, and metabolic intensity of sauropod dinosaurs. Proc R Soc Lond B Biol Sci 267:1883-1887.

Seymour R.S., P.C. Withers, and W.W. Weathers. 1998. Energetics of burrowing, running, and free-living in the Namib Desert golden mole (Eremitalpa namibensis). J Zool (Lond) 244:107-117.

Shaner R.F. 1962. Comparative development of the bulbus and ventricles of the vertebrate heart with special reference to Spitzer's theory of heart malformations. Anat Rec 142:519529.

Shelton G. and D.R. Jones. 1991. The physiology of the alligator heart: the cardiac cycle. J Exp Biol 158:539-564.

Thomas R.D.K. and E.C. Olson. 1980. A Cold Look at the Warm-Blooded Dinosaurs. American Association for the Advancement of Science, Washington, D.C.

Ultsch G.R. and D.C. Jackson. 1982. Long-term submergence at $3^{\circ} \mathrm{C}$ of the turtle, Chrysemys picta bellii, in normoxic and severely hypoxic water. I. Survival, gas exchange, and acidbase status. J Exp Biol 96:11-28.

Vinegar A., V.H. Hutchison, and H.G. Dowling. 1970. Metab- olism, energetics, and thermoregulation during brooding of snakes of the genus Python (Reptilia, Boidae). Zoologica 55: $19-48$.

Walker A.D. 1970. A revision of the Jurassic reptile Hallopus victor (Marsh), with remarks on the classification of crocodiles. Philos Trans R Soc Lond B 257:323-372.

Wang T., J. Altimiras, and M. Axelsson. 2002. Intracardiac flow separation in an in situ perfused heart from Burmese python Python molurus. J Exp Biol 205:2717-2723.

Wang T., J. Altimiras, W. Klein, and M. Axelsson. 2003. Ventricular haemodynamics in Python molurus: separation of pulmonary and systemic pressures. J Exp Biol 206:42414245.

Wang T., D.R. Carrier, and J.W. Hicks. 1997. Ventilation and gas exchange in lizards during treadmill exercise. J Exp Biol 200:2629-2639.

Wang T., A.W. Smits, and W.W. Burggren. 1998. Pulmonary function in reptiles. Pp. 297-374 in C. Gans and A.S. Gaunt, eds. Biology of the Reptilia. Morphology G: Visceral Organs. Society for the Study of Amphibians and Reptiles, Ithaca, N.Y.

Webb G.J.W. 1979. Comparative cardiac anatomy of the Reptilia. III. The heart of crocodilians and an hypothesis on the completion of the interventricular septum of crocodilians and birds. J Morphol 161:221-240.

Webb G.J.W. and C. Gans. 1982. Galloping in Crocodylus johnstoni: a reflection of terrestrial activity? Rec Aust Mus 34: 607-618.

Webb G.J.W., G.C. Sack, R. Buckworth, and S.C. Manolis. 1983. An examination of Crocodylus porosus nests in two northern Australia freshwater swamps, with an analysis of embryo mortality. Aust Wildl Res 10:571-605.

Wettstein O.V. 1954. Crocodilia 2. Pp. 321-424 in W. Kükenthal, T. Krumbach, J.G. Helmcke, and H. van Lengerken, eds. Handbuch der Zoologie. Eine Naturgeschicte der Stämme des Tierreiches. de Gruyter, Berlin.

White F.N. 1969. Redistribution of cardiac output in the diving alligator. Copeia 1969:567-570.

- 1970. Central vascular shunts and their control in reptiles. Fed Proc 29:1149-1153.

White F.N., J.W. Hicks, and A. Ishimatsu. 1989. Relationship between respiratory state and intracardiac shunts in turtles. Am J Physiol 256:R240-R247.

Xu X., Z.-I. Tang, and X.-L. Wang. 1999a. A therizinosauroid dinosaur with integumentary structures from China. Nature 399:350-354.

Xu X., X.-L. Wang, and X.-C. Wu. 1999b. A dromaeosaurid dinosaur with a filamentous integument from Yixian Formation of China. Nature 401:262-266.

Young B.A., H.B. Lillywhite, and R.J. Wassersug. 1993. On the structure of the aortic valves in snakes (Reptilia: Serpentes). J Morphol 216:141-159.

Zug G.R. 1974. Crocodilian galloping: an unique gait for reptiles. Copeia 1974:550-552. 